\title{
Pädiatrietage der ÖGKJ 2019, Venedig
}

\author{
Trotz aqua alta wieder ausgebucht.
}

Bereits zum achten Mal trafen sich Kinderärztinnen und -ärzte zum Erfahrungsaustausch im Rahmen der Pädiatrietage der Österreichischen Gesellschaft für Kinder- und Jugendheilkunde von 21. bis 22. November 2019 in Venedig. Diese Tagung mit ihrem hochkarätigen wissenschaftlichen Programm und den namhaftesten Referentinnen und Referenten zu pädiatrischen Themen ist bereits seit mehreren Jahren ein Fixpunkt im Fortbildungskalender der deutschsprachigen Kinderärzte geworden.

Seit dem Jahr 2012 finden jährlich zu Winterbeginn die Pädiatrietage der Österreichischen Gesellschaft für Kinderund Jugendheilkunde im Zentrum von Venedig statt. Jedes Jahr treffen sich
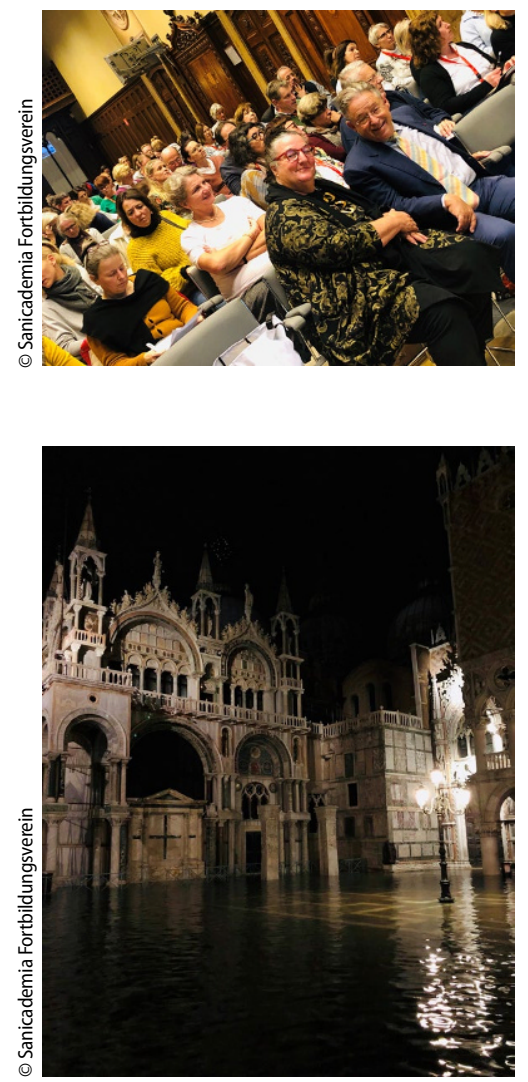

rund 200 Teilnehmer in dem hervorragenden Kongresszentrum in Oberitalien zum intensiven wissenschaftlichen Erfahrungsaustausch. So auch im November 2019 trotz einer dramatischen Hochwassersituation in diesen Tagen in Venedig, und die Teilnehmer wurden mit einem ausgezeichneten wissenschaftlichen Programm entschädigt.

„Das Besondere an dieser beliebten Fortbildungsveranstaltung ist die außergewöhnliche Zusammenstellung des Programmes. Die Pädiatrietage in Venedig befassen sich neben Aktuellem aus der Kinder- und Jugendheilkunde auch mit Themen, welche nicht direkt in unser Fachgebiet fallen, uns Kinderärzte aber stets in unserem Arbeitsalltag begleiten. Dieses Programm bietet uns damit eine enorme Wissensbereicherung und hilft oft bei einer Diagnosestellung und der Weitervermittlung an Kolleginnen und Kollegen anderer Fächer", berichtet Prim. Univ. Prof. Dr. Wolfgang Sperl, Leiter der Universitätsklinik für Kinder- und Jugendheilkunde in Salzburg.

Großen Wert legt der wissenschaftliche Tagungsleiter - Prim.

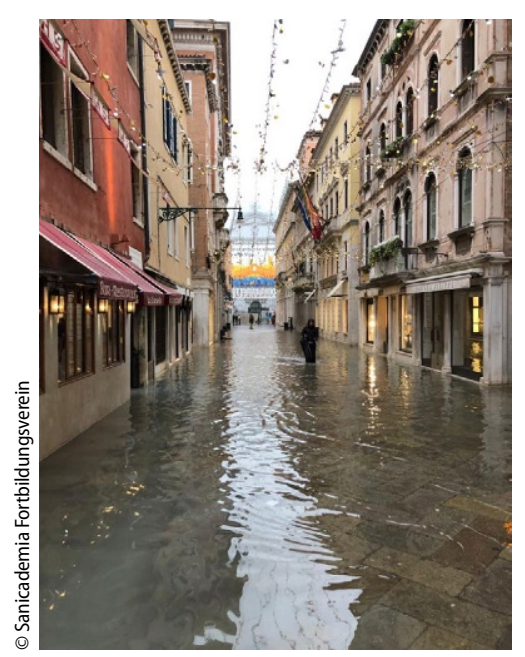

Prof. Dr. Robert Birnbacher - jedes Jahr auf die Einbettung von Themenschwerpunkten, welche bei anderen Tagungen wenig Raum finden und trotzdem - oder gerade deshalb - von großem Interesse für Pädiater sind. Dies können praxisorientierte Vorträge aus der Neuropädiatrie, Sozialpädiatrie, Allergologie, Endokrinologie, Phoniatrie, Ernährung u.a.m. sein. Gerade das wichtige Thema der frühkindlichen Ernährung findet jährlich ihren Platz in der Programmzusammenstellung.

Diese thematische Vielfalt und die herausragenden Sprecherinnen und Sprecher begeistern nicht allein Kinderärzte, auch die Industrie ist von Beginn an gerne Teil einer begleitenden Industrieausstellung. Diese ist in den Kongresspausen beliebter Rahmen für Fachdiskussionen unter Kollegen und somit ein Fixbestandteil dieser erfolgreichen Tagung.

Die Kinderärzte dürfen sich bereits auf den nächsten wissenschaftlichen Gedankenaustausch an der AccademiaBrücke von 19. bis 20. November 2020 freuen. Eine zeitnahe Voranmeldung wird empfohlen, da die Tagung seit Jahren immer rasch ausgebucht ist.

\section{Weitere Informationen:}

www.sanicademia.eu

Hinweis des Verlags. Der Verlag bleibt in Hinblick auf geografische Zuordnungen und Gebietsbezeichnungen in veröffentlichten Karten und Institutsadressen neutral.

Paediatr. Paedolog. 2020 · 55:94 https://doi.org/10.1007/s00608020-00760-x

(c) Springer-Verlag GmbH Austria, ein Teil von Springer Nature 2020 